\title{
Tarsis en la Estela de Nora: ¿un topónimo de Occidente?
}

Arcadio Del CASTILlo *

Universidad de Alicante

El texto conocido con el nombre de Estela de Nora, hallada en 1773 y conservada desde 1830 en el museo de Cagliari, debe ser analizado para cualquier estudio referente a la Tarsis que se menciona en el Antiguo Testamento. Tras varios intentos por resolver su contenido, y gran número de interpretaciones, terminó siendo incorporada al Corpus Inscriptionum Semiticarum, donde se llegaba a la conclusión de que se trataba de una estela conmemorativa de Ros, hijo de Nagid, que vivió en Cerdeña, en la que se especificaba que su nieto Meleciaton el Lipisano completó lo que convenía para erigirla ${ }^{1}$. Y así fue recogido después por $\mathrm{M}$. Lidzbarski $^{2}$ y por G. A. Cooke ${ }^{3}$.

*arcadio.castillo@ua.es.

Este trabajo ha sido llevado a cabo en el Institute of Classical Studies, en la School of Oriental and African Studies, en el Warburg Institute y en la British Library durante nuestra estancia en Londres en enero de 2001.

${ }^{1} C I S$ I, no 144, pág. 192 (cf. tab. XXXII): [ms]|bt řs š|ngd šh'|bšrdn š|lmh ’̌ l|nsb' m|lktn bn r|š bn ngd|lpsy «Cippus Rosi, (filii) Nagidi, qui (habitavit) in Sardinia. Absolvit quod ad erigendum illud (pertinebat) Melec(ja)ton, filius Rosi, filii Nagidi, Lipisanus». La bibliografía más antigua aparece en págs. 190-191.

${ }^{2}$ M. LIDZBARSKI, Handbuch der nordsemitischen Epigraphik nebst ausgewählten Inschriften, I (Weimar 1898) pág. 427 (cf. II, Tf. II, 3; en adelante, esta obra se citará como NES); ID., Altsemitische Texte, I. Kanaanäische Inschriften (Moabitisch, Althebräisch, Phönizisch, Punisch) (Giessen 1907) nº6, pág. 47 (en adelante, esta obra se citará como $K I$ ); en ambos sin la traducción.

${ }^{3}$ G. A. Cooke, A Text-Book of North-Semitic Inscriptions. Moabite, Hebrew, Phoenician, Aramaic, Nabataean, Palmyrene, Jewish (Oxford 1903) nº 41, pág. 110 (en adelante, esta obra se citará como NSI); su traducción en pág. 111, sigue la

Sefarad 63 (2003) págs. 3-32

(c) CSIC

ISSN 037-0894 
La aparición del trabajo de W. F. Albright propició una nueva avalancha de interpretaciones por parte de los investigadores. Frente a la anterior transcripción -que posibilitaba la necesidad de una primera línea reconstruida, en la que proponía solamente $m s$, que junto a las dos primeras letras de la siguiente, esto es, $b t$, daba la traducción de 'estela'-, W. F. Albright mantenía la necesidad de una importante reconstrucción en toda la parte izquierda de la inscripción. Este autor llegaba así a la conclusión de que se trataba de una inscripción mucho mayor, compuesta seguramente por varias lápidas, siendo la que conocemos únicamente la parte inferior derecha ${ }^{4}$, razón por la cual no resulta posible una reconstrucción total, pero en la que se denota que se trata del texto de un decreto de destierro ${ }^{5}$. Respecto a la referencia a Tarsis que aparece en el texto, Albright considera que no puede ser Tartessos, en la Península Ibérica, sino que se trataría del nombre fenicio de la misma Nora o de un asentamiento vecino ${ }^{6}$.

del CIS: «Pillar of Rosh, (son) of Nagid, who (dwelt) in Sardinia; Milk-(ya)thon, son of Rosh, son of Nagid, (the) Liphsite, completed it (?), (even that) which (was required) for setting it up».

${ }^{4}$ W. F. AlBright, «New Light on the Early History of Phoenician Colonization», BASOR 83 (1941) págs. 18-19. Cf. ID., «The Role of the Canaanites in the History of Civilization», en The Bible and the Ancient Near East. Essays in honor of William Foxwell Albright, ed. G. E. WRIGHT (Garden City 1961; reimpr. Winona Lake 1979) Appendix I, págs. 346 y 360 n. 95a. Incluso, basándose en la opinión de B. Mazar, considera que realmente está también incompleta en la parte derecha: cf. ID., «Books on the Archaeology of Palestine, Syria and Phoenicia», BASOR 189 (1968) pág. 55; ID., «Syria, the Philistines, and Phoenicia», CAH II-2 (3 ${ }^{\mathrm{a}}$ ed. Cambridge 1975) pág. 523. J. TEIXIDOR («Bulletin d'épigraphie sémitique», Syria 45 [1968] pág. 371) apoya la idea de que el texto está incompleto.

5 W. F. Albright, «New Light on the Early History...», pág. 19 (cf. pág. 18,

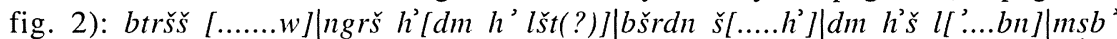
m[hnt wbn mm]|lkt wbn [skn (?) w'm y]|šb wngr[ś h'dm h']|bymy «in (from?) Tarshish [...... and] that $\mathrm{m}[\mathrm{an}]$ shall be banished [for a year(?)] from Sardinia [........ that] man who had $\mathrm{n}$ [ot ...... whether] (he be) commander of a h[ost or (he be) ki]ng or (he be [governor(?). And if he shall] return, then [that man] shall be banish[ed] for his life-time(?)». Cf. ID., «The Role of the Canaanites...», pág. 346; ID., «Syria, the Philistines...», pág. 523.

6 W. F. Albright, «New Light on the Early History...», pág. 21. Cf. ID., «Recent Publications Received by the Editor, I. Near-Eastern Archaeology», BASOR 95 (1944) pág. 38; ID., «The Role of the Canaanites...», págs. 347 y $361 \mathrm{n}$. 
Partiendo de la premisa de que en la estela se aludía a Tarsis, A. Mentz consideró que la inscripción estaba completa, y que refería que Habis fue expulsado de Tarsis, el príncipe de pleno derecho, esto es, totalmente legítimo, pero recibió compensación, pues el rey Taw lo llevó de vuelta a Nora mediante una guerra, siendo el amo en la entrada del agua (estrecho de Gibraltar) ${ }^{7}$. Según este autor, al haber convertido el rey Taw de Cerdeña a Habis en amo del estrecho de Gibraltar, éste ostentaba realmente el dominio de Tartessos ${ }^{8}$, puesto que Mentz acepta la identificación de Tarsis con Tartessos ${ }^{9}$.

En cambio, A. Dupont-Sommer, que mantuvo igualmente que la inscripción estaba completa, se inclinó por estimar que ésta conmemoraba la erección del templo del cabo de Nora, en Cerdeña, con deseo de prosperidad para él y para Tiro, madre de Kition y de Narnaka (Larnaka), en Chipre, especificando que el referido templo fue construido por los colonos fenicios de Nora en honor del dios $\mathrm{Pu}-$ may ${ }^{10}$. Estos colonos de Nora procederían de Chipre, lo que queda reflejado en la referencia a Pumay, dios de la isla, y en la propia alusión a ésta junto a Tiro ${ }^{11}$.

103. Cf., sin embargo, ID., «Syria, the Philistines...», págs. 525-526, donde se sugiere la posibilidad de que originariamente fuera Tharros en Cerdeña.

7 A. MENTZ, Beiträge zur Deutung der phönizischen Inschriften, Abhandlungen für die Kunde des Morgenlandes XXIX, 2 (Leipzig 1944) pág. 18: btř̌š $\mid$ ngrš $h^{\prime} \mid b$ $\check{s} r d n \check{s} \mid l m h$ ' $h^{\prime}\left|m s b^{\prime} m\right| l k$ tw $b g r \mid \breve{s} b w$ ngd|lp my «In Tarschisch wurde vertrieben H’b, der Fürst völligen Rechts (d. h. der völlig rechtmässige Fürst). Er erhielt Vergeltung. Durch einen Krieg führte ihn König Tw in Nora zurück, der Herr am Eingang des Wassers».

8 A. MENTZ, Beiträge zur Deutung..., pág. 21.

9 A. MENTZ, Beiträge zur Deutung..., págs. 23-24.

10 A. DUPONT-SOMmer, «Nouvelle lecture d'une inscription phénicienne archaïque de Nora, en Sardaigne (CIS I, 144)», CRAI (1948) pág. 15 (cf. pág. 14, fig. 1):

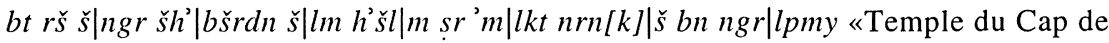
Nogar qui est en Sardaigne. Prospère soit-il! Prospère soit Tyr, mère de Kition (et) Narna[ka] (?)! Lequel (temple) a bâti Nogar en l'honneur de Pumaï»; cf. pág. 21. El autor mantuvo la misma interpretación en un trabajo posterior: «L'inscription punique récemment découverte à Pyrgi (Italie)», JA 252 (1964) pág. 301.

1 A. DUPONT-SOMmer, «Nouvelle lecture d'une inscription...», págs. 20-21. 
Vemos, pues, que el problema fundamental radicaba, como desde antiguo, en el hecho de que en la Estela de Nora no existen trazos de separación entre las distintas palabras, con lo que se complica de forma notable cualquier interpretación que se pretenda hacer. Y, al margen de algunas posibles diferencias de interpretación en otras líneas, el punto capital reside justo en la primera de ellas, pues ésta admite las posibles interpretaciones de $b t r \check{s} \breve{s}$, que sería 'templo del cabo de (que)', o bien btřšs, que daría 'a (en, de) Tarsis'. Por ello, las diferentes interpretaciones girarán en torno a tales parámetros. Pero no queremos dejar de reseñar, por su interés como precedentes, las interpretaciones realizadas por Guil. Gesenius en relación al primer caso, y por G. Arri y F. Benary al segundo.

Guil. Gesenius supuso que en la inscripción, un título sepulcral, se hacía referencia a la casa del pater Sardorum, quien, siendo un amante de la paz, hizo que ésta llegase al reino de Ben-Rosch, hijo de Nagid, quien a la postre era el dedicante ${ }^{12}$; el autor considera seguro el nombre del dedicante, aunque expresa ciertas dudas respecto al gentilicio L-ensis, referido a Ben-Rosch ${ }^{13}$.

G. Arri, por su parte, había considerado, unos años antes, que se trataba de una inscripción votiva en honor del héroe epónimo de Cerdeña, esto es, Pater Sardon, advirtiendo que la referida inscripción relataba que el pío Padre Sardon se había hecho a la mar partiendo de Tarsis, para llegar finalmente al término de su viaje, momento en el que ordenó fuese escrita una lápida en Nora, la cual suponía que estaba enfrente de Lixus ${ }^{14}$. Por lo tanto, este autor era

12 GUIL. GeSEnIUS, Scripturae linguaeque phoeniciae monumenta quotquot supersunt, Pars Prima. Duos priores de litteris et inscriptionibus phoeniciis libros continens (Lipsiae 1837) pág. 156 (cf. tab. 13, $\mathrm{n}^{\circ} \mathrm{XLI}$ ): bt rš š|ngd šh'|b šrdn š|lm h' $\check{s} l\left|m y b^{\prime} m\right| l k t n$ bn $r \mid \check{s}$ bn ngd|lpmy «Domus capitis (i.e. dormitorium) principis, qui (erat) pater Sardorum. Pacis amans ille, pax contingat regno nostro. Ben-Rosch, filius Nagidi, L-ensis».

13 Gull. Gesenius, Scripturae linguaeque phoeniciae monumenta..., pág. 157.

14 G. ARRI, «Lapide fenicia di Nora in Sardegna», MAT 38 (1835) pág. 89 (cf.

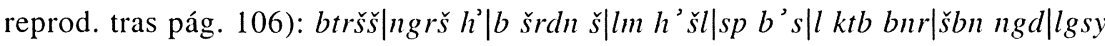
«In Tarschisch vela dedit pater Sardon pius, viae tandem finem attingens lapidem 
partidario de que Sardon llegó a Cerdeña inmediatamente desde Tarsis, y conjetura que primero habría partido de Lixus, en Mauritania Tingitana ${ }^{15}$, afirmando al mismo tiempo que Tarsis se encontraba en la Hispania Bética, en concreto en la vecindad del estrecho de Gibraltar ${ }^{16}$.

En cambio, F. Benary, con la misma transcripción que el anterior respecto a la primera línea ${ }^{17}$, planteó dos posibles interpretaciones, según se tuviese en consideración o no la existencia de un símbolo que le parecía que estaba insertado en algunas letras, y que podría haber servido para destacar un nombre propio o localidad, o para algún otro propósito: 1) si no se tiene en cuenta la existencia del símbolo, estaríamos ante un decreto en el que se especificaba, por una orden expresa, que quien fuese expulsado de Tartessos estaría a salvo en Cerdeña, y a salvo ingresaría en ese reino, fuese pobre o príncipe $^{18}$;2) si se tiene en cuenta el símbolo, entonces se trataría de un título sepulcral, en el que se desea la paz para Malchitten el Lafmita, que era hijo de Rosch y nieto de Nagid, y que fue exiliado a Tartessos, encontrando la paz en Cerdeña ${ }^{19}$. Los más recientes intentos de interpretación de la Estela de Nora, como veremos, son bastante deudores de la segunda de las propuestas de este investigador.

En un principio, la primera de las soluciones pareció tomar ventaja sobre la segunda. Y las subsiguientes interpretaciones, con pun-

scribi jussit in Nora, quam Lixo novit adversam». Cf. ID., «De lingua phoenicum», MAT serie seconda 1 (1839) tab. $\mathrm{n}^{\mathrm{o}} \mathrm{IV}$, donde aparece una nueva reproducción de la inscripción.

${ }^{15}$ G. ARRI, «Lapide fenicia...», pág. 97 (cf. pág. 106).

${ }^{16}$ G. ARRI, «Lapide fenicia...», pág. 98 (cf. pág. 106).

${ }^{17}$ F. BENARY, recensión a G. Arri, en Jahrbücher für Wissenschaftliche Kritik, 1836, II. Bd., n' ${ }^{\circ}$ 8-9, col. 64 (cf. reprod. en col. 61): btršš $\mid$ ngrš $h^{\prime}|b s ̌ r d n ~ s ̌| l m ~ h '$ $\check{s} l\left|m y b^{\prime} m\right| l k t n$ bn $r \mid \check{s}$ bn ngd|lpmy.

${ }^{18}$ F. BENARY, recensión a G. Arri, en Jahrbücher..., col. 64: «Tartessi expulsus, hic in Sardis incolumis, hic incolumis ingrediatur regnum nostrum, sive pauper sit sive princeps iussu meo».

${ }^{19}$ F. BENARY, recensión a G. Arri, en Jahrbücher..., col. 64: «In Tartessus war er ein Vertriebener, in Sardinien war er in Frieden; Frieden komme über Malchitten, den Sohn Rosch, des Sohnes Nagid, den Lafmiten». 
tuales variantes, así lo apuntaban (todas ellas con la particularidad de considerar que la inscripción estaba completa). Así se puede constatar en la de J.-G. Février, donde se pone de manifiesto que $N g r$-un antropónimo-, que era de $\breve{S} r d n$ (indicación no de Cerdeña en su totalidad, sino de una ciudad o territorio del interior de la isla), edificó el templo principal, que él había llevado la tarea de la obra, y que lo había construido en honor del dios Pumay ${ }^{20}$.

Del mismo modo, en la interpretación de A. van den Branden se dice que se trata de una inscripción de construcción, en la que se mencionan las diferentes fases que llevaron a la finalización completa del templo: la primera fase consistió en la construcción del templo principal por Naggâr, habitante de la ciudad de Cerdeña (que probablemente debe de identificarse con Nora, la cual, debido a su importancia, habría podido dar su nombre a la isla entera); éste, sin embargo, quedó inacabado, por lo que en la segunda fase el mismo Naggâr se había dedicado a la construcción de un templo secundario en honor de Pumay; dicho templo también había quedado sin terminar, puesto que en una tercera fase se había dedicado a la ejecución de una serie de trabajos en este santuario dedicado a Pumay ${ }^{21}$.

Asimismo, la interpretación de H. Donner y W. Röllig sigue muy de cerca la de A. Dupont-Sommer, en el sentido de que supone la erección de un templo en el cabo de $\mathrm{Ngr}$, en Cerdeña, especificando el deseo de prosperidad para él y para Tiro, madre de Kition, y señalando que $\mathrm{Ngr}$ (la colonia de $\mathrm{Ngr}$ ) lo había construido para Pumay ${ }^{22}$.

\footnotetext{
${ }^{20}$ J.-G. FÉVRIER, «L'Inscription archaïque de Nora», $R A 44$ (1950) págs. 124 y 126: bt ršs š|ngr $\check{s} h^{\prime}|b s ̌ r d n ~ s ̌| l m ~ h ' s ̌ l\left|m ~ s b^{\prime} m\right| l k t$ nbn[t]|š bn ngr|lpmy «Temple principal, que NGR, qui est à (en?) ŠRDN, a édifié complètement. Lui a mené à bout la tâche de l'oeuvre. Construction qu'a construite NGR en l'honneur de PMY».

${ }^{21}$ A. VAN DEN BRANDEN, «L'inscription phénicienne de Nora (CIS I, 144)», Al-Ma-

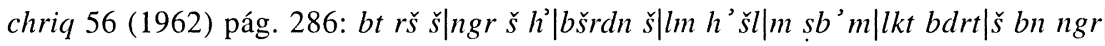
lpmy «Temple principal que Naggâr qui est de Sardaigne a achevé. (C'est) lui (encore qui) a achevé la série de travaux dans le sanctuaire qu'a construit Naggâr à Pumay».

22 H. DONNER y W. RÖlLIG, Kanaanäische und aramäische Inschriften (Wiesbaden 1962-1964) nº 46, I, pág. 10 y II, pág. 63 (cf. III, Tf. II; en adelante, esta obra

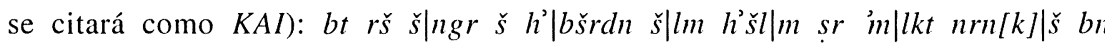


J. Ferron, por su parte, considera que la inscripción intenta transmitir a la posteridad que el templo al que se hace referencia fue el primero erigido por los fenicios en Cerdeña, para pasar a continuación a plantear el deseo de que se conserve intacto el templo edificado por la ciudad de Nora en honor de Pumay ${ }^{23}$.

Finalmente, M. Delcor se inclina por la construcción de un templo en el cabo de Nugar (que supone que es un topónimo sardo anterior a la ocupación fenicia) y de su estela en honor del dios Pumay, precisando que la estela fue obra de Melekyaton y el templo se edificó por iniciativa del Nagid, indudablemente el príncipe de Nora ${ }^{24}$.

A todo ello habría que sumar la transcripción de M. G. Guzzo Amadasi, que dice haberla realizado mediante el examen directo de la lápida, pero que se ha basado en las interpretaciones de J.-G. Février y A. Dupont-Sommer para llevar a cabo la división de las palabras ${ }^{25}$. Respecto a la propia lápida, esta autora, mediante un examen directo, ha puesto de manifiesto su integridad a derecha e

ngr|lpmy «Tempel (am) Kap von NGR(?), dem, das (liegt) in Sardinien - Heil sei ihm! Heil sei Tyros, der Mutter von Kition! .... welchen NGR gebaut hat dem $\mathrm{PMJ}$. Estos autores prefirieron obviar la referencia a Narna[ka] por considerarla muy dudosa.

${ }^{23}$ J. FERRON, «La pierre inscrite de Nora», RSO 41 (1966) págs. 285 y 288 (cf. pl. I-II): bt řs $\check{s}\left|n q d \check{s} h^{\prime}\right| b \check{s} d r n s ̌\left|l m h^{\prime}{ }^{\prime} l\right| m s b^{\prime} m|l k t w b n| \check{s} b n n r^{\prime} \mid l p m y$ «(Ce) Temple (est) le premier qui a été consacré en Sardaigne. Qu'il soit (conservé) intact! Que soit (conservée) intacte l'oeuvre de maçonnerie et d'architecture qu' a édifiée Nora en l'honneur de Poumaï!». Pese a lo establecido en la línea tercera, traduce 'Cerdeña', pues piensa que los autores de la inscripción pronunciaban y escribían así el nombre del país en virtud de una metátesis que no tiene nada de extraño (pág. 286).

${ }^{24}$ M. DELCOR, «Réflexions sur l'inscription phénicienne de Nora en Sardaigne», Syria 45 (1968) págs. 331 y 351 (cf. pág. 329, fig. 2): bt rš š $\mid n g r$ šh'|bšrdn š|lm h' $\check{s} l\left|m s b^{\prime} m\right| l k t n b n|s ̌ b n n g d| l p m y$ «Temple du cap de Nugar qui est en Sardaigne. Qu'il soit conservé dans son intégrité! Que soit conservée dans son intégrité (sa) stèle que Melekyaton a bâtie! Lequel (temple), le prince l'a bâti en l'honneur de Pumaï»; cf. págs. 351-352.

${ }^{25}$ M. G. GuZzo AmadASI, Le iscrizioni fenicie e puniche delle colonie in Occidente, Studi Semitici 28 (Roma 1967) pág. 84 (cf. tav. XXVII): bt ršs š|ngd(r) $\check{s} h^{\prime}|b \check{s} r d n \check{s}| l m h^{\prime} \check{s} l\left|m s b^{\prime} m\right| l k t n(m) b n|s ̌ b n n g d(r)| l p m y$. 
izquierda, haciendo notar, asimismo, que en la parte superior presenta una superficie algo irregular y que quizás podría estar rota ${ }^{26}$.

Por otra parte, M. Dahood, en una recensión al libro de esta autora, considera que se trata de una referencia a la restauración del templo de $\mathrm{Ngr}$ (tal vez Nora), que estaba en Cerdeña, construido por $N g r$ en honor de Pumay, y que tal reconstrucción fue llevada a cabo por el ejército de la reina ${ }^{27}$.

Por último, señalaremos que, en 1974, A. Dupont-Sommer, apoyándose en la interpretación de J.-G. Février, cambió la referencia a 'Narna[ka]' por la de 'construcción', de forma que la inscripción aludiría a la erección del templo del cabo de Nora, en Cerdeña, con deseo de prosperidad para él y para Tiro, madre de Kition, en Chipre, incidiendo en que su construcción había sido realizada por los colonos fenicios de Nora en honor del dios Pumay ${ }^{28}$.

Así pues, en todos los casos que acabamos de reseñar se considera que la lectura correcta de la primera línea de la Estela de Nora es $b t r \check{s} \check{s}$. A pesar de que esta lectura tiene la ventaja de que se ajusta a un formulario conocido ${ }^{29}$, lo cierto es que las últimas aportaciones al respecto han tendido a incidir expresamente en la posibilidad de que la lectura correcta sea $b$ trššs.

${ }^{26}$ M. G. Guzzo AmAdASI, Le iscrizioni fenicie e puniche..., págs. 84-85.

${ }^{27}$ M. DAHOOD, recensión a M. G. Guzzo Amadasi, en Orientalia NS 38 (1969) pág. 159: bt ršš š|ngr šh'|b̌s ruined temple of NGR (= Nora?) which is in Sardinia, has been restored. The edifice which NGR built for Pumay was restored by the army of the queen».

${ }^{28}$ A. DuPONT-SOMmer, «Les phéniciens à Chypre», RDAC (1974) pág. 83 (cf. págs. 83-84 n. 3): «Temple du Cap de Nogar qui est en Sardaigne. Prospère soit-il! Prospère soit Tyr, mère de Kition! Construction qu'a construite Nogar en l'honneur de Pumaï». Incluso aceptaba que se podría traducir también «Temple principal de Nogar», en lugar de «Temple du Cap de Nogar» (pág. 83 n. 2). Asimismo, K. GALLING parece apoyar esta interpretación («Der Weg der Phöniker nach Tarsis in literarischer und archäologischer Sicht», ZDPV 88 [1972] pág. 148).

${ }^{29}$ G. Bunnens, L'expansion phénicienne en Méditerranée. Essai d'interprétation fondé sur une analyse des traditions littéraires, Études de Philologie, d'Archéologie et d'Histoire Anciennes publiées par l'Institut Historique Belge de Rome XVII (Bruxelles - Rome 1979) pág. 32. 
De este modo, B. Peckham ha considerado que la inscripción -que en su opinión está completa y de la que ha realizado una transcripción interpretando que la primera letra de la línea segunda es una $w$, y que hay que leer una $d$ (ya presente en transcripciones anteriores) en lugar de $r$ en la última letra de la línea séptima ${ }^{30}$ - fue realizada y dedicada por Milkûtôn para honrar al dios Pmy, cuando él y el ejército bajo su mando fueron expulsados de Tarsis y encontraron refugio en Cerdeña ${ }^{31}$. Este autor incide en que la expulsión de Milkûtôn, como enemigo o aliado, parece implicar que él y su ejército habían mantenido alguna forma de permanencia continuada en Tarsis ${ }^{32}$, y que, puesto que las fuerzas fenicias eran considerables, habida cuenta del título ostentado por el oficial al mando, su derrota y expulsión de Tarsis fueron un evento de cierta importancia, aunque su significación histórica permanezca oscura ${ }^{33}$. Concluye, con ello, que hay evidencias de que los fenicios pretendían establecerse, aunque no en Cerdeña, y que, puesto que no tuvieron éxito, Tarsis -donde los fenicios habrían tratado de establecer una colonia a principios del siglo IX a.C.- mantenía una posición consolidada con suficiente fortaleza para proteger su propio territorio en oposición a cualquier intento de explotación sistemática por los fenicios, por lo que la llegada de éstos a Cerdeña no era, evidentemente, su propósito inicial ${ }^{34}$. En lo que se refiere a la localización de Tarsis, manifiesta, en principio, que lo que resulta claro es que no puede ser identificada con Cerdeña, dado que a ella se llegó tras la expulsión de Tarsis, y no se inclina por ninguna de

${ }^{30} \mathrm{Cf}$., sin embargo, lo apuntado por G. BUNNENS, L'expansion phénicienne..., págs. 33, 37 y n. 38 .

31 B. PECKHAM, «The Nora Inscription», Orientalia NS 41 (1972) pág. 459:

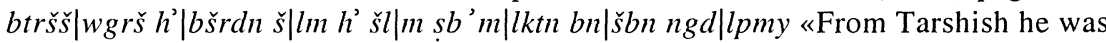
driven, in Sardinia he found refuge, his forces found refuge: Milkûtôn, son of Šûbôn, the commander. To Pmy». La referencia a Cerdeña es considerada a la isla en su totalidad, y no a un lugar concreto (pág. 463).

32 B. PECKHAM, «The Nora Inscription», pág. 463.

33 B. PECKHAM, «The Nora Inscription», pág. 465.

34 B. PECKHAM, «The Nora Inscription», pág. 467. 
las dos ubicaciones que toma en consideración, a saber, el oeste, en la Península Ibérica, y el este, en Tarso de Cilicia ${ }^{35}$; concluye por estimar, sin embargo, que el Mediterráneo Occidental, y el sur de la Península Ibérica en particular, ofrecían las condiciones mínimas para una colonización, dada la existencia de asentamientos fenicios en un tiempo ligeramente posterior ${ }^{36}$.

Por su parte, F. M. Cross asume la transcripción realizada por B. Peckham (si bien en este caso la transcripción se ofrece vocalizada), aunque opina que la inscripción se halla incompleta, faltando dos líneas en la cabecera, y concluye que celebra la victoria de las fuerzas fenicias, al mando de Milkatōn, hijo de Šūbnā, general del rey Pumay, sobre las tribus nativas de Cerdeña en la batalla de Tarsis -que piensa era un lugar de Cerdeña, presumiblemente Nora o un lugar cercano-, lo que habría dado lugar a que se estableciese la paz ${ }^{37}$. Este autor supone que Tiro había enviado un ejército a Cerdeña, hacia el 825 a.C., para pacificar a las tribus nativas y proteger sus intereses mineros, por lo que la inscripción es clara evidencia del éxito de los fenicios en colonizar la isla, y apoya la idea de que no más tarde del siglo IX a.C. Tiro estaba involucrada en la colonización sistemática del Mediterráneo Occidental ${ }^{38}$.

En cambio, E. Lipiński, desdeña la transcripción de B. Peckham, y además estima que en la inscripción faltan dos líneas al principio, considerando que evoca el peligro corrido en el mar y la salvación final de una tripulación, encabezada por un oficial del rey de Kition de Chipre, mientras que el barco, que navegaba hacia Tarsis, fue llevado

\footnotetext{
35 B. PECKHAM, «The Nora Inscription», pág. 460.

36 B. PECKHAM, «The Nora Inscription», págs. 467-468.
}

${ }^{37}$ F. M. CROSS, «An Interpretation of the Nora Stone», BASOR 208 (1972) págs. 15-16 (cf. pág. 14, fig. 1): [hiltahim (?)]|[’itt šardina (?)]|batarš ‘̌s|wagarrišo hü'|bašardina ša|lim hü'šal|im saba'o- mi|lkatōn bin|šübnänag ìd|lapummay «[He fought (?)] [with the Sardinians (?)] at Taršǐš, and he drove them out. Among the Sardinians he is [now] at peace, (and) his army is at peace: Milkatōn son of Šūbnā (Shebna), general of (king) Pummay». Pummay sería un hipocorístico del nombre del rey Pigmalión de Tiro, quien habría reinado entre los años 831 y 785 a.C. (pág. 17).

${ }^{38}$ F. M. CROSS, «An Interpretation of the Nora Stone», pág. 18. 
a la deriva y encalló felizmente en Cerdeña, donde los supervivientes llevaron a cabo una dedicatoria al dios Pumay consistente en una construcción edificada por el heraldo ${ }^{39}$. Este autor plantea asimismo que, en el caso de que la inscripción estuviese completa, el barco del rey de Kition no habría navegado hacia Tarsis, sino que se trataría del viaje de regreso, con lo que haría referencia a que desde Tarsis fue arrastrado a Cerdeña; allí, la tripulación del rey encontró la salvación, por lo que el oficial al mando edificó una construcción para Pumay ${ }^{40}$. En cualquier caso, la hipótesis de la integridad de la inscripción le parece a Lipiński difícil de defender ${ }^{41}$. Respecto a Tarsis, este autor no considera que se pueda asegurar que haya que identificarla con Tartessos, y manifiesta que debe ser localizada al oeste de Cerdeña, la cual se encontraba en la ruta de una de las vías de expansión comercial de los fenicios en Occidente ${ }^{42}$. En un nuevo trabajo, diez años después, Lipiński ha considerado aceptable la corrección $w$ por $n$ en el comienzo de la segunda línea, aunque ello no ha cambiado básicamente su interpretación del texto ${ }^{43}$.

Tratando de realizar una recapitulación sobre el tema, G. Bunnens ha señalado que la Estela de Nora debe de recoger una dedicatoria a una divinidad, de nombre Pmy, realizada por los fenicios en la isla

\footnotetext{
${ }^{39}$ E. LIPINSKI, «Tartessos et la stèle de Nora», en Segundo Congreso Internacional de Estudios sobre las Culturas del Mediterráneo Occidental (Trabajos leidos en Barcelona, 29 Septiembre - 4 Octubre 1975) (Barcelona 1978) págs. 73-

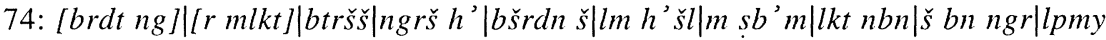
"[Quand le héraut] [du roi de Kition descendait] sur Tarshish, lui-même fut emporté en Sardaigne. Il est sain et sauf, lui. Sain et sauf est l'équipage du roi de Kition. Construction que le héraut a bâtie pour Pummay».

40 E. LIPIŃSKI, «Tartessos et la stèle de Nora», pág. 74: «De Tarshish, il fut emporté. En Sardaigne, il est sain et sauf. Sain et sauf est l'équipage du roi de Kition. Construction que le héraut a bâtie pour Pummay».

${ }^{41}$ E. LIPINSKKI, «Tartessos et la stèle de Nora», pág. 74

${ }^{42}$ E. LIPINSKI, «Tartessos et la stèle de Nora», pág. 73.

${ }^{43}$ E. LIPINSKI, «Carthage et Tarshish», BiOr 45 (1988) col. 63: «[Le héraut du roi] [de Kition s'était embarqué] à Tarshish et lui-même fut emporté en Sardaigne. Il est sain et sauf, lui. Sain et sauf est l'équipage du roi de Kition. Construction que le héraut a bâtie pour Pummay».
} 
de Cerdeña ${ }^{44}$, y da por segura una transcripción sin segmentación, que se basa en las anteriormente realizadas ${ }^{45}$, de la que podrían desprenderse dos posibles interpretaciones, ambas, según este autor, con importantes inconvenientes, ya sea que fuese una referencia a la erección de un templo o bien a Tarsis. La primera interpretación consistiría en la conmemoración de la construcción, por parte del oficial al mando, de un templo en un cabo que se encontraba en Cerdeña, en honor de Pmy, con el deseo expreso de paz para el templo y para el ejército real ${ }^{46}$. De la segunda se deduciría que desde Tarsis había sido llevado a la deriva a Cerdeña, donde encontró la salvación para él y para el ejército real, razón por la cual el oficial al mando habría construido un monumento en honor a Pmy ${ }^{47}$. Respecto a la estela en sí, resulta muy interesante que este autor manifieste que ahora puede verse en su totalidad, puesto que ha sido levantada y se puede observar que existe una peana en el centro de la base destinada a fijarla sobre un pedestal, al tiempo que resulta incuestionable que se encuentra completa, con la única salvedad tal vez de la parte superior, que, por lo demás, resulta ser más estrecha que la base ${ }^{48}$.

Posteriormente, J. C. L. Gibson, siguiendo fielmente la transcripción de B. Peckham para realizar una no segmentada ${ }^{49}$, se muestra

${ }^{44}$ G. BUNNENS, L'expansion phénicienne..., pág. 38. Cf. ID., «Aspects religieux de l'expansion phénicienne», en Studia Phoenicia, IV. Religio Phoenicia, Collection d'Études Classiques 1, eds. C. BONNET, E. LIPINSKI y P. MARCHETTI (Namur 1986) pág. 119.

${ }^{45}$ G. BUNNENS, L'expansion phénicienne..., pág. 31 (cf. pl. I-II): btršš $\mid w(n$ ?)gršh'|bšrdnš|lmh'šl |mssb'm|lktnbn|šbnngr|lpmy.

${ }^{46}$ G. Bunnens, L'expansion phénicienne..., pág. 37: «Temple de (du cap de?) ... qui, quant à lui, (se trouve) en Sardaigne. Qu'il soit en paix! Que soit en paix la troupe royale. Monument que le commandant a construit pour Pmy».

47 G. Bunnens, L'expansion phénicienne..., pág. 38: «En Tšš (Tarshish) il a derivé. En Sardaigne il a trouvé le salut. Sauve est la troupe royale. Monument que le (son?) commandant a construit pour Pmy».

${ }^{48}$ G. Bunnens, L'expansion phénicienne..., pág. 31.

49 J. C. L. Gibson, Textbook of Syrian Semitic Inscriptions, III. Phoenician Inscriptions including Inscriptions in the Mixed Dialect of Arslan Tash (Oxford 1982) $\mathrm{n}^{\circ} 11$, pág. 26 (cf. pl. II, 2; en adelante, esta obra se citará como SSI): btršš wgršh'|bšrdnš|lmh'šl|mssb'm|lktnbn|šbnngd|lpmy. 
partidario, como W. F. Albright, de que la inscripción, incompleta, era la esquina inferior derecha de una inscripción mucho más grande. Por ello, se inclina por la solución de que se trata de la conmemoración de la construcción de un templo, de forma que la inscripción parece que acabaría con el nombre de la persona responsable, encargada de llevar a cabo la obra, y una anotación de la fecha en que fue concluida ${ }^{50}$.

W. H. Shea, utilizando también la misma transcripción, si bien con una nueva variante, consistente en concreto en cambiar $n$ por $m$ en la tercera letra de la línea octava, además de suponer la falta de una línea en la cabecera, ha propuesto una nueva interpretación: Milkaton, hijo de Šubon, el anterior oficial al mando, junto con su ejército, fue al Mediterráneo Occidental para llevar a cabo una campaña y penetró en Cerdeña durante su viaje de retorno, y en la inscripción pone de manifiesto que no había sufrido daños ni pérdidas en los enfrentamientos que había tenido ${ }^{51}$. Respecto a la localización de Tarsis, se muestra partidario de la Península Ibérica ${ }^{52}$.

Finalmente, suprimiendo el añadido del principio, A. J. Frendo se ha inclinado por sostener que se trata de una referencia a que Milkaton, hijo de Šabon, el anterior oficial al mando, al cual sucedió, hubo de enfrentarse a dificultades durante sus operaciones en Tarsis, por lo que la población de ese lugar le expulsó junto con su ejército, encontrando feliz refugio en Cerdeña ${ }^{53}$. Respecto a Tarsis, no especifica nada sobre su localización ${ }^{54}$.

$50 \quad$ SSI III, $\mathrm{n}^{\circ} 11$, pág. 28.

51 W. H. SHEA, «The Dedication on the Nora Stone», VT 41 (1991) págs. 243244: [grš h']|btršš $\left|w g r \check{s} h^{\prime}\right| b \check{s} r d n$ š $\mid$ lm h'šl $\left|m s b^{\prime} m\right| l k t n$ bn|šbn ngd|lpny «[He drove out] at Tarshish, and he drove out in Sardinia. He is safe. His troops are safe. Milkaton, son of Shubon the previous commander».

52 W. H. SHEA, «The Dedication on the Nora Stone», pág. 244.

53 A. J. FRENDO, «The Particules beth and waw and the Periodic Structure of the Nora Stone Inscription», PEQ 128 (1996) pág. 9: btř̌š $\left|w g r \check{s} h^{\prime}\right| b \check{s} r d n$ š $\left|\operatorname{lm} h^{\prime} \check{s}^{\prime}\right| m$ $s b^{\prime} m|l k t n b n| s ̌ b n n g d \mid l p n y$ «He was indeed expelled from Tarshish; in Sardinia he is [now] safe, safe is his army [too]; Milkaton, son of Shabon, the previous commander»; cf. pág. 11 .

54 A. J. FRENDO, «The Particules beth and waw and the Periodic Structure...», pág. 11. 
Por lo que se refiere a la cronología de la Estela de Nora, se ha considerado que se trata de la más antigua de las inscripciones fenicias de Occidente, siendo fechada por buena parte de la investigación en el siglo IX a.C. ${ }^{55}$ Tal datación se ha apoyado en el análisis

${ }^{55}$ Así, por ejemplo, R. Dussaud, «Les inscriptions phéniciennes du tombeau d'Ahiram, roi de Byblos», Syria 5 (1924) págs. 147 y 156 (finales del siglo IX a.C.); ID., recensión a A. Dupont-Sommer, en Syria 26 (1949) pág. 390; H. BAUER, «Eine phönikische Inschrift aus dem 13. Jahrh», OLZ 28 (1925) col. 138 (finales del siglo IX a.C.); Fr. W. vON BISSING, «Die sardinischen Bronzen», MDAI(R) 43 (1928) pág. 25; W. F. AlbRight, «New Light on the Early History...», pág. 20 (primera mitad del siglo IX a.C., con fechas extremas hacia 925-825 a.C.); ID., «The Role of the Canaanites...», pág. 346 y 361 n. 103; ID., «Books on the Archaeology...», pág. 38; ID., «Syria, the Philistines...», pág. 523; A. MENTZ, Beiträge zur Deutung..., pág. 15; S. MAZZARINO, Fra Oriente e Occidente. Ricerche di storia greca arcaica (Firenze 1947) pág. 317; A. DUPONT-SOMMER, «Nouvelle lecture d'une inscription...», págs. 12-13 y 20-21; ID., «L'inscription punique...», págs. 300-301; ID., «Les phéniciens à Chypre», págs. 82 y 84; J. BÉRARD, La colonisation grecque de l'Italie méridionale et de la Sicile dans l'Antiquité. L'Histoire et la Légende (2a ed. Paris 1957) pág. 72; G. PESCE, Sardegna punica (Cagliari 1961) pág. 52; A. VAN DEN BRANDEN, «L'inscription phénicienne de Nora...», pág. 284; KAI n 46, II, pág. 63 (tal vez del siglo IX a.C.); B. MAZAR, The Philistines and the rise of Israel and Tyre, Proceedings of the Israel Academy of Sciences and Humanities I, 7 (Jerusalem 1964) pág. 17; J. FERRON, «La pierre inscrite de Nora», pág. 288; S. M. CECCHINI, I ritrovamenti fenici e punici in Sardegna, Pubblicazioni del Centro di Studio per la Civiltà Fenicia e Punica 2, Studi Semitici 32 (Roma 1969) pág. 61; B. PECKHAM, «The Nora Inscription», págs. $466-467$ (principios del siglo IX a.C.); F. M. CROSS, «An Interpretation of the Nora Stone», págs. 14 y 18 (siglo IX a.C., presumiblemente en su segunda mitad); O. MASSON y M. SZNYCER, Recherches sur les phéniciens à Chipre, Centre de Recherches d'Histoire et de Philologie de la IVe Section de l'École Pratique des Hautes Études II. Hautes Études Orientales 3 (Genève - Paris 1972) pág. 14 (cf. n. 4); H. J. KATZENSTEIN, The History of Tyre. From the Beginning of the Second Millenium B.C.E. until the Fall of the Neo-Babylonian Empire in 538 B.C.E. (Jerusalem 1973) pág. 186; E. LIPINSKI, «Tartessos et la stèle de Nora», pág. 76; ID., "Carthage et Tarshish», col. 63 (fin del siglo IX a.C.); G. BUNNENS, L'expansion phénicienne..., pág. 40 (primera mitad del siglo IX a.C.); ID., «Aspects religieux...», pág. 119; SSI III, n 11, pág. 25 (principios o mediados del siglo IX a.C.); M. ElAT, «Tarshish and the Problem of Phoenician Colonisation in the Western Mediterranean», OLP 13 (1982) pág. 59; W. RöLLIG, «Paläographische Beobachtungen zum ersten Auftreten der Phönizier in Sardinien», en Antidoron. Festschrift für Jürgen Thimme zum 65. Geburtstag am 26. September 1982, eds. D. Metzler, B. OtTo y Chr. Müller-Wirth (Karlsruhe 1983) pág. 
paleográfico de la propia inscripción, que ha llevado a considerar que es ligeramente anterior a la inscripción de Kilamuwa de Sam'al, actual Zencirli en Turquía ${ }^{56}$, y que tiene su paralelo más próximo

127 (hacia mediados del siglo IX a.C.); W. H. SHEA, «The Dedication on the Nora Stone», pág. 244; M. YoN, «Le royaume de Kition. Époque archaïque», en Studia Phoenicia, V. Phoenicia and the East Mediterranean in the First Millenium B.C., Orientalia Lovaniensia Analecta 22, ed. E. LIPIŃSKI (Leuven 1987) pág. 364. Consideran que habría que situarla entre los siglos IX y VIII a.C.: D. DIRINGER, L'alfabeto nella storia della civiltà (Firenze 1937) pág. 408, fig. 171, 1 (aunque posteriormente, en The Alphabet. A Key to the History of Mankind (reimpr. London 1953) pág. 246, la fecha a principios del siglo IX a.C.); E. FrÉZOULS, «Une nouvelle hypothèse sur la fondation de Carthage», $B C H 79$ (1955) pág. 170 n. 1; F. Barreca, Sardegna: L'espansione fenicia nel Mediterraneo, Pubblicazioni del Centro di Studio per la Civiltà Fenicia e Punica 8, Studi Semitici 38 (Roma 1971) pág. 11; E. GJERSTAD, «The Phoenician Colonization and Expansion in Cyprus», RDAC (1979) págs. 237 n. 3; M. KoCH, Tarschisch und Hispanien. Historichgeographische und namenkundliche Untersuchungen zur phönikischen Kolonisation der iberischen Halbinsel, Madrider Forschungen 14 (Berlin 1984) pág. 103 n. 1; asimismo, Mh. H. FANTAR, Los fenicios en el Mediterráneo (Barcelona 1999) pág. 98 (si bien antes, en pág. 25, considera que podría fecharse en el siglo IX a.C.).

56 Son abundantes los trabajos referentes a esta inscripción. Entre los más recientes se pueden consultar: F. M. Cross y D. N. FreEdMAN, Early Hebrew Orthography. A Study of the Epigraphic Evidence, American Oriental Series 36 (New Haven 1952) págs. 15-19 (estudios anteriores se citan en págs. 11-12 n. 2); S. HERRMANN, «Bemerkungen zur Inschrift des Königs Kilamuwa von Senğirli», OLZ 48 (1953) cols. 295-297; KAI n 24, I, págs. 4-5 y II, págs. 30-34 (cf. III, Tf. XXVII); J. B. PRITCHARD, Ancient Near Eastern Texts Relating to the Old Testament ( $3^{a}$ ed. con suplemento, Princeton 1969) pág. 654 (en adelante, esta obra se citará como ANET); T. COLLINS, «The Kilamuwa Inscription - a Phoenician Poem», WO 6 (1971) págs. 183-188; L. A. BANGE, A Study of the Use of Vowel-Letters in Alphabetic Consonantal Writing (München 1971) págs. 35-41; P. MAGNANINI, Le iscrizioni fenicie dell'Oriente. Testi, traduzioni, glossari (Roma 1973) págs. 45-47; E. LIPINSSI, «From Karatepe to Pyrgi: Middle Phoenician Miscellanea», RStFen 2 (1974) págs. 49-50; A. VAN DEN BRANDEN, «Quelques notes concernant le vocabulaire phenico-punique», RStFen 2 (1974) págs. 140-141; Y. AvisHuR, «Studies of Stylistic Features Common to the Phoenician Inscriptions and the Bible», UF 8 (1976) págs. 11, 15 y 17-18; M. O'CONNOR, «The Rhetoric of the Kilamuwa Inscription», BASOR 226 (1977) págs. 15-29; G. GARBINI, «L'iscrizione fenicia di Kilamuwa e il verbo $\breve{s k}$ in semitico nordoccidentale», Bibbia e Oriente 19 (1977) págs. 113-118; SSI III, nº 13, págs. 30-39 (cf. pág. 183, fig. 10). Cf. J. TEIXIDOR, «Bulletin d'épigraphie sémitique», Syria 50 (1973) págs. 421-422; 52 (1975) pág. 281; 56 (1979) pág. 384. 
en una inscripción funeraria del Museo de Nicosia en Chipre ${ }^{57}$. En ésta se aprecia, sin embargo, la existencia de trazos de separación entre las palabras, lo que es un signo de arcaísmo que, sin embargo, no aparece en la Estela de Nora.

A este respecto, algunos investigadores han hecho notar la inexistencia de hallazgos arqueológicos que puedan corroborar la llegada de los fenicios a Cerdeña en la fecha referida, así como que en la Estela de Nora aparece una escritura arcaizante, que siguió siendo utilizada en una zona como Cerdeña, la cual, por encontrarse aislada de Fenicia, no pudo seguir su misma evolución. Por estas razones, los hay que se han inclinado por suponerla del siglo vIII a.C. ${ }^{58}$, mientras que otros la han rebajado al VII a.C. ${ }^{59}$, o incluso al VI-V a.C. ${ }^{60}$

57 A. M. Honeyman, «The Phoenician Inscriptions of the Cyprus Museum», Iraq 6 (1939) nº 8, págs. 106-108 (cf. pl. XIX, fig. 3); W. F. ALBRIGHT, «New Light on the Early History...», págs. 15-17; A. DUPONT-SOMMER, «Une inscription phénicienne archaïque de Chypre», RA 41 (1947) págs. 201-211; KAI nº 30, I, pág. 7 y II, págs. 48-49 (cf. III, Tf. III); O. MASSON y M. SZNYCER, Recherches..., págs. 13-20 (cf. pl. II-III); P. MAGNANini, Le iscrizioni fenicie..., pág. 134; H.-P. MÜLLER, «Die phönizische Grabinschrift aus dem Zypern-Museum KAI 30 und die Formgeschichte des nordwestsemitischen Epitaphs», ZA 65 (1975) págs. 104-132; E. PUECH, «Remarques sur quelques inscriptions phéniciennes de Chypre», Semitica 29 (1979) págs. 19-26; SSI III, nº 12, págs. 28-30 (cf. pl. I, 3). Cf. J. TEIXIDOR, «Bulletin d'épigraphie sémitique», Syria 46 (1969) pág. 336.

${ }^{58}$ G. LILliU, «Rapporti fra civiltà nuragica e la civiltà fenicio-punica in Sardegna», SE 18 (1944) pág. 345 n. 16; ID., recensión a W. F. Albright, en SS 8 (1948) pág. 440; H. L. LORIMER, Homer and the Monuments (London 1950) pág. 66 (primera mitad del siglo viII a.C.); G. R. DrIVER, Semitic Writing from Pictograph to Alphabet, The Schweich Lectures of the British Academy 1944 (London 1948; reed. 1976) pág. 107 (segunda mitad del siglo VIII a.C.) y pág. 127 (725-700 a.C.); M. G. GUZZO AMADASI, Le iscrizioni fenicie e puniche..., pág. 83 y n. 1; U. TÄCKHOLM, «Neue Studien zum Tarsis-Tartessosproblem», ORom 10 (1974) pág. 43; K. Galling, «Der Weg der Phöniker nach Tarsis...», pág. 149 (segunda mitad del siglo Vill a.C.).

59 R. CARPENTER, «The Antiquity of the Greek Alphabet», AJA 37 (1933) pág. 15 , considera que habría que situarla dentro de la colonización cartaginesa de la isla a finales del siglo vil a.C., y en el caso de que fuese realmente fenicia se situaría en el momento de penetración fenicia en aguas itálicas, no antes de finales del siglo VIII a.C.; P. CinTas, Céramique punique, Publications de l'Institut des 
No obstante, habría que tener en cuenta, como hace G. Bunnens, que la inscripción funeraria de Chipre, lugar muy cercano a Fenicia, presenta las mismas características que la Estela de Nora, y que un parecido tan estrecho, sin grandes variantes locales, solamente se puede explicar si ambos documentos resultan ser rigurosamente contemporáneos ${ }^{61}$. Naturalmente, se puede argumentar en contra de esta apreciación que los hallazgos arqueológicos existentes no son anteriores al siglo VIII a.C., pero hemos de tener en cuenta que las mismas fuentes griegas nos dicen que los fenicios les precedieron. Y resulta obvio que la inexistencia de restos materiales no puede ser nunca una prueba definitiva para negar la veracidad de las fuentes. Así, por ejemplo, la invasión del Peloponeso por los eslavos a finales del siglo VI y principios del VII ha dejado escasos restos a nivel arqueológico que atestigüen tal acontecimiento, lo que no pone en entredicho que la invasión tuviese lugar. De hecho, se llevó a cabo de forma masiva ${ }^{62}$. Por lo demás, no nos parece totalmente

Hautes Études de Tunis III (Paris 1950) pág. 581 n. 631 (posiblemente de finales del siglo VII a.C.); G. GARBINI, «Note di epigrafia punica - II», RSO 42 (1967) pág. 3; ID., «Considerazioni conclusive», en Fenici e Arabi nel Mediterraneo (Roma, 12-13 ottobre 1982) (Roma 1983) pág. 160.

${ }^{60}$ Tal vez del siglo VI a.C: NES I, págs. 120 y 177; KI $\mathrm{n}^{\circ} 60$, pág. 47; NSI $\mathrm{n}^{\circ} 41$, pág. 111; Z. S. HARRIS, A Grammar of the Phoenician Language, American Oriental Series 8 (New Haven 1936) pág. 157. Cf., en cambio, H. S. SCHUSTER, «Der Relativsatz im phönizischen und punischen», en Studies in Honor of Benno Landsberger on his Seventy-Fifth Birthday. April 21, 1965, Assyriological Studies 16 (Chicago 1965) pág. 440, que la data hacia finales del siglo VI a.C.; y R. CARPENTER, «Phoenicians in the West», AJA 62 (1958) pág. 48, que la lleva a los siglos VI-V a.C.

${ }^{61}$ G. Bunnens, L'expansion phénicienne..., pág. 40. Cf. W. F. Albright, «New Light on the Early History...», pág. 20.

${ }^{62}$ M. S. F. Hood, «An Aspect of the Slav Invasions of Greece in the Early Byzantine Period», Sborník Národního Muzea v Praze (Acta Musei Nationalis Pragae) 20 (1966) págs. 165 ss. Cf. M. S. F. Hood, en Bronze Migrations in the Aegean. Archaeological and Linguistic Problems in Greek Prehistory, eds. R. A. Crossland y A. Birchall (Park Ridge 1974) págs. 238-239 (asimismo, D. J. BlACKMAN, pág. 318); A. DEl CASTILlo, «Las invasiones en Grecia y la Edad Oscura», en Manual de Historia Universal, III. El mundo griego, ed. A. MONTENEGRO DUQUE (Madrid 1987) pág. 92. 
asumible como argumento mantener que los diversos hallazgos arqueológicos muy antiguos deben ser rechazados simplemente por tratarse de elementos aislados, como tampoco decir que los fenicios utilizaban objetos egipcios antiguos procedentes de robos de tumbas para transportar sus mercancías ${ }^{63}$, en un intento por desdeñar los restos más remotos encontrados en Occidente. Todo ello sin olvidar que las inscripciones de Cerdeña no son hechos aislados: son algo definitivo. Y solamente cabría discutir su cronología, pero el análisis paleográfico no deja lugar a dudas sobre la antigüedad de las mismas.

Ahora bien, no es nuestro propósito llevar a cabo una nueva transcripción que pueda conllevar, asimismo, una nueva interpretación. Consideramos que las posibilidades para ello resultan prácticamente nulas, habida cuenta de la abundancia de las existentes. Lo que realmente pretendemos es efectuar un análisis de aquellas que han considerado que en la Estela de Nora se hace referencia a Tarsis, y que tal localidad se encontraba ubicada en el Occidente. En general, los autores de estas interpretaciones se muestran partidarios de fechar la inscripción en el siglo IX a.C. ${ }^{64}$

Examinaremos, en primer lugar, aquellas interpretaciones que han tendido a localizarla, dentro del Occidente, en la Península Ibérica $\mathrm{y}$, con mayor o menor claridad, en Tartessos.

G. Arri y A. Mentz insertan sus interpretaciones en contextos legendarios, lo que ya las pone en entredicho. Ahora bien, dejando al margen tal hecho, habría que apuntar lo siguente:

- Respecto a la interpretación de G. Arri, lo cierto es que parece poco asumible que un barco que parte de un puerto fenicio, a saber Lixus, no tenga como escala en la Península Ibérica el también puerto fenicio de Gadir, sino Tarsis, que obviamente situándola donde la sitúa debe de identificarla con Tartessos, porque si existían Lixus y Tartessos, habría de existir Gadir, dado que Tartessos es precisamente

${ }^{63}$ Cf., por ejemplo, M. E. Aubet, Tiro y las colonias fenicias de Occidente (Barcelona 1987) págs. 183-184.

${ }^{64}$ Véase nota 55. 
el resultado de los contactos fenicios. Concretamente, su creación viene determinada por el impacto de tales $\operatorname{contactos}{ }^{65}$. Y no se puede aceptar la posibilidad de que se esté confundiendo Tartessos con Gadir, como se aprecia en algunas fuentes, porque esta confusión es consecuencia, precisamente, de la desaparición de la propia Tartessos, y no ocurre antes de que este hecho se produzca ${ }^{66}$.

- La interpretación de A. Mentz se caracteriza por ser muy original, pero hay que tener en cuenta que el único texto que hace referencia a Habis, el de Pompeyo Trogo ${ }^{67}$, denota la existencia de problemas de este monarca con su antecesor Gargoris ${ }^{68}$, pero de ninguna forma se puede deducir del relato que Habis fuese expulsado de Tartessos y luego fuera ayudado por un rey de Cerdeña. Si tal hubiera sucedido en el mito, alguna fuente clásica se habría hecho eco de ello, especialmente el propio Pompeyo Trogo. Y, en cualquier caso, habría que preguntarse qué sentido tiene que los fenicios coloquen una estela en Cerdeña y en ella hagan referencias a un mito relacionado con la civilización tartéssica.

En cuanto a la interpretación de F. Benary, su propuesta tiene bastante relación con las sugeridas posteriormente por B. Peckham, F. M. Cross, W. H. Shea y A. J. Frendo, por lo que lo apuntado para ellos valdrá también para este autor.

Por su parte, sobre la localización de Tarsis, B. Peckham propone el sur de la Península Ibérica o Tarso de Cilicia. En cualquiera de los dos supuestos, ¿por qué huir a Cerdeña? En el primero de los casos lo natural hubiera sido refugiarse en Gadir, si como es lógico pensar ya existía, porque, de lo contrario, ¿qué hacían los fenicios allí? No estarían en la zona de Tartessos, habida cuenta de que

${ }^{65}$ Cf., en general, A. DEl CASTILlo, La caída de Tartessos como explicación para la formación de una estructura política (León 1988) págs. 81-82.

66 A. DEl CASTILlo, La caída de Tartessos como explicación..., pág. 44.

67 Justino, Epit., 44, 4, 1-14.

${ }^{68}$ Cf., sobre las interpretaciones de este texto, A. DEl CASTIllo, La caída de Tartessos como explicación..., págs. 52 ss. 
Gadir se fundó precisamente para estar en las proximidades de Tartessos y, como ya hemos indicado, fue una consecuencia del influjo fenicio ${ }^{69}$. En el segundo caso, lo normal habría sido huir hacia la misma Fenicia, más próxima que Cerdeña. Y, por otra parte, habría que preguntarse qué hacía un ejército considerable en Tarsis. ¿Colonizar? Nada más contrario a la forma fenicia de hacerlo. Y si los fenicios intentaban establecer una colonia en el oeste, a principios del siglo IX a.C., entonces es forzoso pensar que se trataría de Gadir, puesto que de lo contrario habrían huido hacia ella; y si lo era, no se corresponde en absoluto con las noticias que poseemos sobre su fundación. Un planteamiento de enfrentamiento armado resultaría más lógico en el Mediterráneo Oriental, pero entonces habrían huido hacia Fenicia. Por lo demás, parece coherente lo que asevera F. M. Cross, a saber, que resulta muy dudoso suponer que un jefe fenicio erigiese un monumento de una envergadura considerable para celebrar su expulsión de Tarsis y haber encontrado la salvación en Cerdeña después de un viaje por $\operatorname{mar}^{70}$.

La interpretación de B. Peckham ha servido a M. Elat para concluir que Tarsis debía de estar ubicada en la Península Ibérica, y que la Estela de Nora es la confirmación de lo apuntado por Pausanias ${ }^{71}$ acerca de la huida de Norax, hijo de Hermes, desde España para encontrar refugio en Cerdeña ${ }^{72}$. Sin embargo, y al margen de que también estamos ante un hecho de carácter mitológico, puesto que este autor sigue a B. Peckham y acepta que los hechos a los que se refiere ocurrieron en el siglo IX a.C., no vemos la razón para suponer que el que un ejército fenicio expulsado de Tarsis, que llevado por las circunstancias terminó buscando una colonización en Cerdeña, implique la confirmación de un hecho mitológico que se supone ocurrió en época anterior.

\footnotetext{
${ }^{69}$ Véase nota 65.

${ }^{70}$ F. M. Cross, «An Interpretation of the Nora Stone», pág. 15.

71 Paus., 10, 17, 5.

72 M. ElAT, «Tarshish and the Problem...», pág. 60.
} 
Respecto a lo manifestado por E. Lipiński, habría que decir, en primer lugar, que parece difícil aceptar la existencia de la falta de dos líneas en la cabecera de la inscripción. La tendencia hacia un estrechamiento en la parte alta ${ }^{73}$ denota que se trata de una cabecera semicircular, y el tamaño de las letras indica que no parece posible que pudiera faltar más de una línea, suponiendo que faltase algo, y en tal caso debería de ser una línea de menos letras que las que tienen las líneas conservadas. Pero, en cualquier caso, ¿qué hacía un barco del rey de Kition en el siglo IX a.C. en Tarsis? ¿A qué había ido? ¿No existía Gadir? Si se trataba de colonizar, lo lógico es que la empresa fuera obra de Tiro, que es además lo que dicen las fuentes respecto al Mediterráneo Occidental. ¿Tarsis al oeste de Cerdeña? ¿En qué lugar? Sólo podía ser un asentamiento fenicio, seguramente de la Península Ibérica, pues Tartessos, el foco naturalmente buscado por sus riquezas, únicamente surgió cuando se produjo el impacto fenicio sobre las estructuras indígenas. ¡Luego debía de existir Gadir! Y respecto a la traducción de $m l k t$ por «rey de Kition», este mismo autor manifiesta que esto queda atestiguado más tarde en Chipre ${ }^{74}$. De manera que ello es cierto, pero más tarde, como queda reflejado por otros epígrafes. En tal sentido, no se puede obviar lo apuntado por P. Cintas, quien indica que la Estela de Nora no puede hablar de Kition, puesto que se sabe por una inscripción contemporánea de Chipre que en la época la ciudad se llamaba Cartago, y no Kition ${ }^{75}$, y que si Cartago es Kition, esta ciudad fue llamada Kition más tarde, pues la isla se llamaba Iadnan, y no aún Kittim, nombre que se encuentra en la Biblia en textos que son todos muy posteriores a la fecha de las inscripciones de Nora y de Cartago de Chipre ${ }^{76}$.

73 Cf. B. PeCKham, «The Nora Inscription», pág. 458; G. BUnNENS, L'expansion phénicienne..., pág. 31 .

74 E. LIPINSKI, «Tartessos et la stèle de Nora», pág. 76 y n. 16.

75 P. Cintas, Manuel d'archéologie punique, I. Histoire et archéologie comparées. Chronologie des temps archä̈ques de Carthage et des villes phéniciennes de l'Ouest (Paris 1970) pág. 85.

76 P. Cintas, Manuel d'archéologie punique, I. Histoire..., pág. 85 n. 322. 
No vamos a entrar a discutir si realmente la Cartago de Chipre hace referencia a Kition o no ${ }^{77}$. Baste señalar que, aunque algunos investigadores modernos han tendido a inclinarse por la posibilidad

77 La Cartago de Chipre aparece citada en las inscripciones de las páteras de Limassol: $C I S$ I, n ${ }^{\circ}$ 5, págs. 22-26, con la bibliografía anterior (cf. tab. IV); NES I, pág. 419 (cf. II, Tf. II, 1); KI n ${ }^{\circ} 17$, pág. 24; NSI nº 11, págs. 52-54; D. DIRINGER, The Alphabet..., pág. 245, fig. 122, 1; KAI n 31, I, pág. 7 y II, págs. 49-50; P. MagnAnini, Le iscrizioni fenicie..., pág. 133; G. BUnNENS, L'expansion phénicienne..., págs. 41-43; SSI III, $\mathrm{n}^{\circ} 17$, págs. 66-68 (cf. pág. 182, fig. 6); M. SZNYCER, «Brèves remarques sur l'inscription phénicienne de Chypre, CIS I, 5», Semitica 35 (1985) págs. 47-50 (cf. pl. IV-Va). Cf. J. TEIXIDOR, «Bulletin d'épigraphie sémitique», Syria 46 (1969) págs. 336-337. Tales inscripciones hacen referencia a qrthdšt, que ha sido puesta en conexión con la Kar-ti-ha-da-as-ti que aparece citada en otras de los reyes asirios Asarhadon y Asurbanipal; en estas últimas inscripciones se cita a la referida ciudad al hacer mención de los nombres de los soberanos de los diez reinos de Iadnan (Chipre), que eran tributarios de los asirios. En Asarhadon aparece en el Prisma B, Col. V, 1. 23: E. SCHRADER (ed.), Keilinschrifliche Bibliothek. Sammlung von assyrischen und babylonischen Texten II (Berlin 1890) págs. 148-149 (en adelante, esta obra se citará como KB); R. C. THOMPSON, The Prisms of Esarhaddon and Ashurbanipal found at Nineveh, 1927-8 (London 1931) pág. 25; R. BORGER, Die Inschriften Asarhaddons Königs von Assyrien, Archiv für Orientforschung Bh. 9 (Graz 1956) n 27 (Nin. A-F, Episode 21), pág. 60, Prisma A, Col. V, 1. 69; cf. J. MÉNANT, Annales des rois d'Assyrie (Paris 1874) pág. 245; D. D. LuCKEnBILl, Ancient Records of Assyria and Babylonia, II. Historical Records of Assyria from Sargon to the End (Chicago 1927) n 690, pág. 266 (en adelante, esta obra se citará como ARAB); ANET, pág. 291; D. J. WISEMAN, «Historical Records of Assyria and Babylonia», en Documents from Old Testament Times, ed. D. W. THOMAS (London 1958) pág. 74; C. SAPORETTI, «Cipro nei testi neoassiri», en Studi ciprioti e rapporti di scavo, II, Biblioteca di antichità cipriote 3 (Roma 1976) pág. 86. Y en Asurbanipal aparece en el Cilindro C, Col. I, 1. 43: S. A. SMITH, Keilschrifttexte Assurbanipals, Königs von Assyrien (668-626 v. CHR.) nach dem in London copirten Grundtext, II (Leipzig 1887) págs. 26 y 28; M. STRECK, Assurbanipal und die letzten assyrischen Könige bis zum Untergange Niniveh's, II. Texte. Die Inschriften Assurbanipals und der letzten assyrischen Könige, Vorderasiatische Bibliothek 7 (Leipzig 1916) págs. 140-141; cf. G. SMITH, History of Assurbanipal, translated from the Cuneiform Inscriptions (London 1871) pág. 32, (fragm.) 1. u; KB II, págs. 240-241, (fragm.) 1. 20; J. MÉnAnt, Annales..., pág. 277; ARAB II, nº 876, pág. 341; ANET, pág. 294; C. SAPORETTI, «Cipro...», pág. 87. 
de que se tratase realmente de Kition ${ }^{78}$, los hay también que se han

${ }^{78}$ J.P. SIX, «Du classement des séries cypriotes», Revue numismatique, troisième série, 1 (1883) pág. 253; E. SCHRADER, «Zur Geographie des assyrischen Reichs», SPAW (1890) págs. 337 ss.; E. MEYER, Geschichte des Altertums, II-2 (2 $2^{\mathrm{a}}$ ed. Stuttgart - Berlin 1931) pág. 86 n. 1 y pág. 126; E. GuERSTAD, The Swedish Cyprus Expedition, IV-2. The Cypro-Geometric, Cypro-Archaic and Cypro-Classical Periods (Stockholm 1948) págs. 436 ss. (esp. pág. 437 n. 2); ID., «The Phoenician Colonization...», págs. 233 ss. (esp. págs. 236-237); E. O. FORRER, «Karthago wurde erst 673-663 v. Chr. gegründet», en Festschrift Franz Dornseiff zum 65. Geburtstag (Leipzig 1953) pág. 89; E. FrÉZOULS, «Une nouvelle hypothèse...», págs. 153 ss. (esp. págs. 169-170); S. MosCATI, Il mondo dei fenici (Milano 1966; reimpr. 1979) págs. 120-121; P. CINTAS, Manuel d'archéologie punique, I. Histoire..., págs. 78-85; V. KARAGEORGHIS, Kition. Mycenaean and Phoenician Discoveries in Cyprus (London 1976) págs. 96 y 109-110; K. NicolaOU, The Historical Topography of Kition, Studies in Mediterranean Archaeology XLIII (Göteborg 1976) págs. 313-314; M. G. GuZzo AMADASI y V. KARAGEORGHIS, Fouilles de Kition, III. Inscriptions phéniciennes (Nicosia 1977) pág. 8; W. F. ALBRIGHT, «The Role of the Canaanites...», págs. 342 y 348; G. BUNNENS, L'expansion phénicienne..., págs. 348 ss. (esp. págs. 351-352); M. YON, «Le royaume de Kition...», págs. 365-367. Cf. la crítica de E. OBERHUMMER, Die Insel Cypern. Eine Landeskunde auf historischer Grundlage, I (München 1903) págs. 13-14; G. HILl, A History of Cyprus, I. To the Conquest by Richard Lion Heart (Cambridge 1940; reimpr. 1949) págs. 102 y 107; H. J. KATZENSTEIn, The History of Tyre..., esp. pág. 241; J. TEIXIDOR, «Early Phoenician Presence in Cyprus. Analysis of Epigraphical Material», en The Archaeology of Cyprus. Recent Developments, ed. N. ROBERTSON (Park Ridge 1975) págs. 125-126; C. BAURAIN, «Un autre nom pour Amathonte de Chypre?», BCH 105 (1981) pág. 371; E. Lipiński, «La Carthage de Chypre», en Studia Phoenicia, II. Histoire phénicienne Orientalia Lovaniensia Analecta 15, eds. E. GubEL, E. LiPIŃSKI y B. SERvaISSOYEZ (Leuven 1983) págs. 212 y 218; A. HERMARY, «Amathonte de Chypre et les phéniciens», en Studia Phoenicia, V. Phoenicia and the East Mediterranean..., págs. 379-380; O. MASSON, «La dédicace à Ba'al du Liban (CIS I, 5) et sa provenance probable de la région de Limassol», Semitica 35 (1985) págs. 45-46. Ciertamente, hay que señalar que existe una inscripción que podría hacer imposible la identificación de la Cartago de Chipre con Kition; se trata de la relación de gastos del templo de Astarté en Kition: CIS I, $\mathrm{n}^{\circ}$ 86, págs. 92-99, con la bibliografía anterior (cf. tab. XII); NSI $\mathrm{n}^{\circ} 20$, págs. 65-70; KI $\mathrm{n}^{\circ} 29$, págs. 29-31; $K A I \mathrm{n}^{\circ} 37$, I, pág. 8 y II, págs. 54-55; A. VAN DEN BRANDEN, «Elenco delle spese del tempio de Cition. CIS 86 A e B», Bibbia e Oriente 8 (1966) págs. 245-262; ID., «Quelques notes...», págs. 141-142; B. PECKHAM, «Notes on a Fifth-Century Phoenician Inscription from Kition, Cyprus (CIS 86)», Orientalia NS 37 (1968) págs. 304-324 (cf. tab. XLIX y L); O. MASSON y M. SZNYCER, Recherches..., págs. 21-68 (cf. pl. IV-V); P. Magnanini, Le iscrizioni fenicie..., págs. 109-111; J. P. HEALEY, «The Kition Tariffs and the Phoenician Cursive Series», BASOR 216 
mostrado partidarios tanto de Amathus ${ }^{79}$ como de Nea Paphos ${ }^{80}$, o de Lemesos ${ }^{81}$. Sin embargo, lo que nos resulta incuestionable es

(1974) págs. 53-60 (cf. reprod. en pág. 54); M. G. GuZzo AmAdasi y V. KARAGEORGHIS, Fouilles de Kition, III. Inscriptions..., ${ }^{\circ}{ }^{\mathrm{C}} 1$, págs. 103-126 (cf. pl. $\mathrm{XV}, 1$ y 3); SSI $\mathrm{n}^{\circ}$ 33, págs. 123-131 (cf. pl. VI). Cf. J. TEIXIDOR, «Bulletin d'épigraphie sémitique», Syria 46 (1969) pág. 338-339; 50 (1973) págs. 423-424; E. PUECH, «Remarques...», págs. 31-34. En esta inscripción aparecen referencias simultáneas a Kition (A 1. 4) y a un cartaginés (B 1. 6), lo que sería un hecho incuestionable si no fuese porque en el segundo caso podría tratarse de un ciudadano de la Cartago de África, tal como sugieren los siguientes autores: E. GJERSTAD, «The Phoenician Civilization...», pág. 239 n. 5; A. VAN DEN BRANDEN, «Elenco delle spese...», pág. 260; B. PECKHAM, «Notes on a Fith Century...», pág. 322; J. TEIXIDOR, «Bulletin d'épigraphie sémitique», Syria 46 (1969) pág. 339; J. P. HEALEY, «The Kition Tariffs...», pág. 57. Sin embargo, estos otros dudan entre un cartaginés de África o de Chipre: CIS I, n 86, pág. 98; NSI nº 20, pág. 69; O. MASSON y M. SZNYCER, Recherches..., pág. 62; SSI III, pág. 131. M. YON («La royaume de Kition...», pág. 367 n. 28) desdeña claramente la posibilidad de que sea un cartaginés de África, con lo que habría de inclinarse por uno de Chipre, como sugieren, por ejemplo: $K I \mathrm{n}^{\circ} 29$, pág. $30 ; K A I \mathrm{n}^{\circ} 31$, II, pág. 49; E. LIPINSSI, «La Carthage de Chypre», pág. 219; G. BunNENS, L'expansion phénicienne..., pág. 353.

79 J. MÉnAnt, Annales..., pág. 245; E. OBERHummer, Die Insel Cypern..., I, pág. 14 (aunque posteriormente plantea la posibilidad triple de que tal vez sea Kition, Amathus o Lemesos, en RE, s.u. Kypros, XII-1, col. 102; cf. también cols. 99-100 y s.u. Lemesos, XII-2, col. 1896); G. HILL, «Amathus», AIPHOS 5 (1937) = Mélanges Émile Boisacq I, pág. 487; ID., A History of Cyprus, I. To the Conquest..., pág. 108, lo considera posible, aunque parece inclinarse más por Lemesos. Cf. la crítica realizada por E. GJERSTAD, The Swedish Cyprus Expedition, IV-2. The Cypro-Geometric..., pág. 437 n. 2; ID., «The Phoenician Colonization...», pág. 235; E. LIPIŃSKI, «La Carthage de Chypre», pág. 216; A. HERMARY, «Amathonte de Chypre...», pág. 380.

80 J. HALÉVY, «Manassé, roi de Juda, et ses contemporains», REJ 2 (1881) pág. 13; A. von GuTSCHMID, «Die Phönicier», en Kleine Schriften II (Leipzig 1890) pág. 50. Cf. la crítica realizada por E. OBerhummer, Die Insel Cypern... I, pág. 14; G. BunNENS, L'expansion phénicienne..., pág. 351; E. LIPIŃSKI, «La Carthage de Chypre», pág. 218.

${ }^{81}$ G. HILl, «Amathus», pág. 487; ID., A History of Cyprus, I. To the Conquest..., pág. 108 n. 1; J. B. PескнAм, The Development of the Late Phoenician Scripts, Harvard Semitic Series XX (Cambridge, Mass. 1968) pág. 14 n. 7; O. MASsON y M. SZNYCER, Recherches..., págs. 62 y 78; H. J. KATZENSTEIn, The History of Tyre..., págs. 85 y 207-208; G. GARBINI, I Fenici. Storia e religione (Napoli 1980) págs. 121-122 (esp. pág. 122); ID., «Considerazioni...», pág. 157; E. LIPIŃSKI, «La Carthage de Chypre», págs. 209 ss. (esp. págs. 216-218 y 234); O. MASSON, «La 
que no parecen existir alusiones a Kition con anterioridad a fines del siglo VIII o principios del VII a.C., fechas en torno a las cuales se pueden datar las más antiguas citas bíblicas sobre Kittim y las que manifiestan el dominio asirio sobre la isla (Sargón II, Senaquerib, Asarhadon y Asurbanipal). Por esta razón, E. Gjerstad ha considerado que el estatuto político habría cambiado en 707 a.C., cuando las ciudades chipriotas fueron sometidas por Sargón II, pasando Kition desde el estado de posesión de Tiro al de reino ${ }^{82}$. M. Yon estima que el estatuto regio pudo haberse establecido en Kition alrededor del 700 a.C., en la época de su hijo y sucesor Senaquerib, aunque tal estatuto fuese conocido de forma explícita sólo más tarde ${ }^{83}$. Desde luego, no parece lógico suponer la existencia de una Kition fuera del dominio de Tiro en el siglo IX a.C. ${ }^{84}$, con lo que difícilmente se podría hablar del gobierno de un rey en ese momento. Y, naturalmente, una Kition fenicia (la Estela de Nora lo es) que no estuviese sometida a Tiro, ¿cómo podría enviar un barco al extremo occidental del Mediterráneo introduciéndose en una zona de hegemonía tiria?

dédicace...», págs. 33-46. Cf. la crítica de E. GJERSTAD, The Swedish Cyprus Expedition, IV-2. The Cypro-Geometric..., pág. 437 n. 2; ID., «The Phoenician Colonization...», págs. 235-236; C. BAurain, «Un autre nom...», pág. 371; M. YON, «Le royaume de Kition...», pág. 366 n. 26; A. HERMARY, «Amathonte de Chypre...», pág. 380.

82 E. GJERSTAD, «The Phoenician Colonization...», pág. 249. Cf., recientemente, A. Swinton, V. IzZet y S. Aguilar Gutiérrez, «Phoenicians in the Mediterranean: degrees and modes of interaction», en Actas del IV Congreso Internacional de Estudios Fenicios y Púnicos. Cádiz, 2 al 6 de Octubre de 1995 (Cádiz 2000) vol. IV, pág. 1903.

${ }^{83}$ M. Yon, «Le royaume de Kition...», págs. 365 y 372.

${ }^{84}$ Un texto de Menandro de Efeso, FGrHist (ed. F. JACOBY) III, C-2, n 783 F4, pág. 792, autor que se basó en crónicas tirias, y que aparece recogido por Flavio Josefo, $A J, 9,14,2$ (284), expone que el rey Eluleo, hacia finales del siglo viII a.C., hubo de hacerse a la mar para someter nuevamente a los habitantes de Kition que se habían rebelado. Ello indica claramente que la referida ciudad chipriota era desde antes dependiente de Tiro (realmente del reino conjunto de Sidón y Tiro): cf. G. BUNNENS, L'expansion phénicienne..., págs. 54 y 351 . 
En cuanto a lo defendido por W. H. Shea, teniendo en cuenta que se muestra claramente partidario de que Tarsis debía de localizarse en la Península Ibérica, vale todo lo dicho para B. Peckham. ¿Un importante contingente de tropas fenicias para efectuar una campaña en el Mediterráneo Occidental en el siglo IX a.C., contra todo lo que denotan las fuentes sobre la colonización fenicia y sus esquemas pacíficos? No se debe olvidar que Justino dice expresamente que, cuando Gadir se encontró con problemas con los nativos de la Península Ibérica, lo que hizo fue llamar en su ayuda a los cartagineses ${ }^{85}$. ¡Para el estilo guerrero, se precisaba de una ciudad con esquemas guerreros de colonización!

Ya hemos hecho alusión a que A. J. Frendo no se inclina por una determinada localización para Tarsis. No obstante, debemos poner de relieve que, apoyándose en la interpretación realizada por este autor, ha vuelto a defender su localización en Tartessos Ju. B. Tsirkin ${ }^{86}$, pese a lo cual este autor se reconoce incapaz de contestar a la sagaz pregunta que se formula a sí mismo, a saber, que si Milkaton, el jefe fenicio, fue expulsado de Tarsis (que supone Tartessos), ¿por qué se dirigió a Cerdeña y no a Gadir, que por entonces ya existía? Por nuestra parte, en este orden de ideas consideramos que, si no existía Gadir, tampoco estarían los fenicios en Tartessos.

En general, podemos decir que:

1) Si la Estela de Nora se enmarca en un esquema militar, en el que tiene lugar una expulsión de Tarsis, en este caso no tiene sentido la huida hacia Cerdeña, pues lo lógico sería que las tropas fenicias hubieran buscado refugio en Gadir; y no es posible pensar que en aquel momento no existía este enclave, porque la existencia de Tartessos se halla en estrecha relación con el impacto fenicio sobre la zona.

85 A. DEl CASTILlo, La caída de Tartessos como explicación..., págs. 73-74 y 85; ID., «El rey Terón y la situación de la Península en época postartéssica», RStFen 21 Suppl. (1993) pág. 53.

${ }^{86}$ Ju. B. TSIRKIN, «The Phoenicians and Tartessos», Gerión 15 (1997) págs. 246-247. 
2) En el supuesto de que la Estela de Nora se relacione con una empresa marítima, y la inscripción se erigiese a consecuencia de una tempestad que llevó a un grupo de fenicios a Cerdeña, también sería obligado citar a Gadir, ya que era el puerto lógico del que habrían partido, habida cuenta de que los minerales procedentes de Tartessos se canalizaban hacia esta ciudad.

Analizaremos, a continución, aquellas otras interpretaciones que han tendido a localizar Tarsis en Cerdeña.

La reconstrucción realizada por W. F. Albright, al margen de los argumentos de naturaleza histórica ${ }^{87}$, es la prueba más definitiva en contra de su interpretación: resulta excesiva. En la actualidad, sabemos con certeza que sólo podría faltar algo, muy poco, al comienzo de la inscripción, como han puesto de manifiesto tanto M. G. Guzzo Amadasi ${ }^{88}$ como B. Peckham ${ }^{89}$, mientras que en ambos laterales no puede faltar nada, como han demostrado también con argumentos definitivos M. G. Guzzo Amadasi ${ }^{90}$, B. Peckham ${ }^{91}$ y G. Bunnens ${ }^{92}$.

Basándose en la interpretación de W. F. Albright, S. Mazzarino, teniendo en cuenta el contexto de la inscripción, ha supuesto que en ella Tarsis es probablemente la misma Nora, y que la circunstancia de que Nora sea designada como Tarsis puede explicarse simplemente pensando que los colonos de Nora provenían de Tartessos de España, lo que le parece la explicación más conveniente ${ }^{93}$. Pero tal planteamiento resulta demasiado rebuscado, sobre todo porque, siendo fenicios los colonos, difícilmente podían provenir de Tartessos. Podrían hacerlo desde Gadir, en el caso de que ya existiese

87 Excelentemente sintetizados por U. TÄCKHOLM, «Tarsis, Tartessos und die Säulen des Herakles», ORom 5 (1965) pág. 159.

${ }_{88}$ M. G. GuZzo AmAdASI, Le iscrizioni fenicie e puniche..., pág. 85.

89 B. PECKHAM, «The Nora Inscription», pág. 458.

90 M. G. GuZzo AmAdASI, Le iscrizioni fenicie e puniche..., pág. 84.

91 B. PECKHAM, «The Nora Inscription», pág. 458 n. 9.

92 G. BunNENS, L'expansion phénicienne..., pág. 31.

93 S. MazZarino, Fra Oriente e Occidente..., pág. 318. 
en el siglo IX a.C., que es la fecha que este autor acepta para la Estela de Nora, pero Tartessos sólo fue identificada con Gadir más tarde, como ya hemos manifestado, no antes de la desaparición de aquella ${ }^{94}$.

En cuanto a la interpretación de F. M. Cross, ya hemos indicado, con referencia a E. Lipiński, que resulta difícil que falten dos líneas precisamente en la cabecera, pues la Estela de Nora presenta un estrechamiento hacia la parte alta que evidencia que se trata de una cabecera semicircular, y, por otra parte, el tamaño de las letras no permite pensar que pueda faltar más de una línea, en el supuesto de que falte algo, y en tal caso debería ser una línea de menos letras que las que ofrecen las líneas existentes. Pero incluso aceptando que falten dos líneas, ¿cómo suponer que, para colonizar Cerdeña, Tiro hubiera enviado un poderoso ejército en 825 a.C., que es la datación propuesta por este autor? Pensar que Tiro llevaba a cabo su colonización al estilo de una ciudad involucrada en los esquemas helenísticos, como era el caso de Cartago, es un planteamiento que no cuadra con lo que sabemos de la primitiva colonización fenicia en Occidente. Por lo demás, resulta muy sorprendente que las fuentes clásicas no aludan en absoluto a una colonización fenicia en Cerdeña realizada con un movimiento de importantes efectivos bélicos.

Ahora bien, resulta bastante claro que, incluso en el supuesto de que el texto de la Estela de Nora se refiriera a Tarsis, no se puede considerar que este lugar se encontrase necesariamente en las cercanías de Cerdeña, porque ni siquiera se puede concluir que los dos momentos a los que hace referencia, esto es, salida de Tarsis y llegada a Cerdeña, sean acontecimientos prácticamente simultáneos, o al menos próximos en el tiempo. Por ello, parece demasiado arriesgado presuponer una identificación de Tarsis con Tartessos sobre la base de este documento.

Por todo cuanto acabamos de expresar, creemos que no es posible tener en cuenta el texto de la Estela de Nora para intentar resolver el problema de la ubicación de Tarsis, y muy especialmente resulta

${ }^{94}$ Véase nota 66. 
indudable que todo se opone a que pueda ser identificada con el emporio tartéssico ${ }^{95}$. Lo cierto es que lo único realmente claro es que los fenicios, conforme a los usos antiguos, lo primero que hacían era construir una casa para la divinidad, de forma que al llegar

${ }^{95}$ Recientemente, P. Bordreull, F. ISRAEl y D. PARDEE, «Deux ostraca paléohébreux de la collection Sh. Moussaïeff: I) Contribution financière obligatoire pour le temple de YHWH. II) Réclamation d'une veuve auprès d'un fonctionnaire», Semitica 46 (1996) págs. 49-61; ID., «King's Command and Widow's Plea: Two New Hebrew Ostraca of the Biblical Period», Near Eastern Archaeology 61 (1998) págs. 3-7, han dado cuenta de la existencia de un ostracon paleo-hebreo, que posiblemente habría de datarse en la segunda mitad del siglo vil a.C., en el que se especifica una contribución obligatoria al templo en "plata de Tarsis"; consideran estos autores que se trataría del segundo epígrafe, tras la Estela de Nora, en que Tarsis aparece citada. Por nuestra parte, estimamos que lo único que se pone de manifiesto una vez más es la existencia de un lugar llamado Tarsis. Por lo que atañe a su identificación con Tartessos, posibilidad que admiten los referidos autores (págs. 55 y 5 , respectivamente), hemos de decir que insisten en argumentos conocidos. Así, se apoyan en Salmos, 72, 10, la inscripción Assur 3916 del rey asirio Asarhadon (680-669 a.C.), y Jonás, 1, 3, cuyos textos dicen lo siguiente: «Los reyes de Tarsis y de las islas le ofrecerán sus dones, y los soberanos de Sheba y de Saba le pagarán tributo», «Los reyes del medio del mar, todos ellos, desde el país Iadanana, el país Iaman, hasta el país Tarsisi, se sometieron bajo mis pies», y «Levantóse Jonás para huir a Tarsis, lejos de la presencia de Yahveh; bajó a Jafo, y halló un barco que iba a partir rumbo a Tarsis. Pagó el pasaje y entró en él para irse con ellos a Tarsis, lejos de Yahveh». Respecto al texto de los Salmos, queremos poner de manifiesto que nada puede llevar a considerar que la referencia a los reyes a los que se refiere sea una indicación de los extremos del mundo, a saber Oriente y el Extremo Occidente (págs. 54-55 y pág. 4, respectivamente); ha de tratarse, como ya manifestamos anteriormente, de lugares comprendidos en la esfera comercial de Israel (A. DEL CASTIllo, la caída de Tartessos como explicación..., págs. 36 y 38), lo que deja el Extremo Occidente fuera de toda posible consideración. Y respecto a la inscripción de Asarhadon (págs. 54 y 4, respectivamente) y al texto del Libro de Jonás (págs. 54 y 4 , respectivamente), tenemos muy avanzados sendos trabajos sobre el particular, en los que profundizamos en las razones que ya dimos para considerar una ubicación oriental de ambas referencias, a saber, en el primer supuesto, que habría de encontrarse dentro de los propios límites del mismo Imperio asirio, y en el segundo, en la idea de que el redactor del Libro de Jonás, en época persa, tenía en mente el funcionamiento en su tiempo del canal del Nilo hacia el mar Rojo (A. DEl CASTILlo, La caída de Tartessos como explicación..., págs. 37 y 38-40). 
a un lugar erigían inmediatamente un altar, donde se sacrificaba y se preparaba el lugar santo en el que se rendía culto a los dioses de la metrópoli y a los del mar y del viaje ${ }^{96}$. Con ello no estamos aceptando sin más la interpretación referida a la construcción de un templo, pero hemos de manifestar que resulta tal vez más coherente.

\section{RESUMEN}

El objeto de este trabajo es analizar las diferentes interpretaciones dadas a la inscripción de la Estela de Nora, la más antigua de las inscripciones fenicias de Occidente. Una crítica exhaustiva de las interpretaciones que han mantenido la existencia de una referencia a Tarsis y su ubicación en Occidente nos ha llevado a concluir que el texto de la Estela de Nora no es definitivo para resolver el problema de la ubicación de la Tarsis bíblica, y desde luego que todo se opone a que pueda ser identificada con Tartessos. Así pues, dado que sabemos que los fenicios, al llegar a un lugar, construían un altar para sacrificar y rendir culto a los dioses de la metrópoli, del mar y del viaje, una interpretación referida a la construcción de un templo parece lo más coherente.

Palabras Clave: Estela de Nora, Cerdeña, inscripción fenicia, Tarsis, colonización fenicia.

\section{SUMMARY}

The aim of this paper is to analyze the different interpretations given to the inscription on the Nora Stone, the oldest of the Phoenician inscriptions in the West. An exhaustive critical study of the interpretations that have assumed a reference to Tarshish and its location in the West has led me to conclude that the text of the Nora Stone does not definitively solve the problem of the site of the biblical Tarshish. Moreover, all the evidence speaks against identifying Tarshish with Tartessos. Therefore, since it is well established that the Phoenicians, when they arrived at a new place, built an altar intended for worship and for the offering of sacrifices to the gods of the metropolis, the sea and travel, the most likely interpretation is that the inscription referred to the building of a temple.

Keywords: Nora Stone, Sardinia, Phoenician inscription, Tarshish, Phoenician colonization.

96 Cf. por ejemplo, A. DuPONT-SOMmER, «Nouvelle lecture d'une inscription...», pág. 22; P. CinTAS, Céramique punique, págs. 581-582; U. TÄCKHOLM, «Tarsis, Tartessos...», pág. 158; M. YON, «Le royaume de Kition...», pág. 369. 